\title{
Euthanasia and assisted suicide for people with an intellectual disability and/or autism spectrum disorder: an examination of nine relevant euthanasia cases in the Netherlands (2012-2016)
}

\author{
Irene Tuffrey-Wijne ${ }^{1 *}$ D, Leopold Curfs $^{2}$, Ilora Finlay ${ }^{3}$ and Sheila Hollins ${ }^{4}$
}

\begin{abstract}
Background: Euthanasia and assisted suicide (EAS) have been legally possible in the Netherlands since 2001, provided that statutory due care criteria are met, including: (a) voluntary and well-considered request; (b) unbearable suffering without prospect of improvement; (c) informing the patient; (d) lack of a reasonable alternative; (e) independent second physician's opinion. 'Unbearable suffering' must have a medical basis, either somatic or psychiatric, but there is no requirement of limited life expectancy. All EAS cases must be reported and are scrutinised by regional review committees (RTE). The purpose of this study was to investigate whether any particular difficulties arise when the EAS due care criteria are applied to patients with an intellectual disability and/or autism spectrum disorder.
\end{abstract}

Methods: The 416 case summaries available on the RTE website (2012-2016) were searched for intellectual disability (6) and autism spectrum disorder (3). Direct content analysis was used on these nine cases.

Results: Assessment of decisional capacity was mentioned in eight cases, but few details given; in two cases, there had been uncertainty or disagreement about capacity. Two patients had progressive somatic conditions. For most, suffering was due to an inability to cope with changing circumstances or increasing dependency; in several cases, suffering was described in terms of characteristics of living with an autism spectrum disorder, rather than an acquired medical condition. Some physicians struggled to understand the patient's perspective. Treatment refusal was a common theme, leading physicians to conclude that EAS was the only remaining option. There was a lack of detail on social circumstances and how patients were informed about their prognosis.

Conclusions: Autonomy and decisional capacity are highly complex for patients with intellectual disabilities and difficult to assess; capacity tests in these cases did not appear sufficiently stringent. Assessment of suffering is particularly difficult for patients who have experienced life-long disability. The sometimes brief time frames and limited number of physicianpatient meetings may not be sufficient to make a decision as serious as EAS. The Dutch EAS due care criteria are not easily applied to people with intellectual disabilities and/or autism spectrum disorder, and do not appear to act as adequate safeguards.

Keywords: Euthanasia, Physician-assisted suicide, Intellectual disabilities, Autism spectrum disorders, Legislation, Decision-making capacity, Netherlands

\footnotetext{
* Correspondence: I.Tuffrey-Wijne@sgul.kingston.ac.uk

'Kingston University \& St George's, University of London, Cranmer Terrace,

London SW7 ORE, UK

Full list of author information is available at the end of the article
} 


\section{Background}

Views on euthanasia and physician-assisted suicide (EAS) differ widely and are often strongly held. At the heart of the debate is a tension in the weight afforded to key principles of medical ethics: respect for patient autonomy, beneficience, nonmaleficence, justice and scope. These latter two also recognise the role of law in protecting citizens from harm. Patient autonomy underpins patient-centered care, and proponents of EAS cite self-determination as an overriding principle, while opponents highlight the relational nature of human autonomy and point out that self-determination is not without its limits [1]. All agree that a physician's duty is to relieve suffering. Proponents argue that death relieves suffering, while opponents emphasise that EAS is incompatible with a physician's duties of beneficence and nonmaleficence.

Interpretation of these ethical principles is reflected in the development of EAS legislation, as well as in arguments opposing such legislation to license doctors to provide lethal drugs under certain specified conditions. The European Association for Palliative Care (EAPC) concluded that it is not possible to achieve consensus on the issue, due to incompatible and clashing normative frameworks [2]. Proponents of EAS in countries without such laws argue that EAS legislation serves to relieve intolerable suffering and promote personal control over dying; that the criteria for EAS laid down by law provide transparency; and that the legal frameworks act as safeguards against illegal practices. Opponents point to difficulties in ensuring that the broadly-worded criteria for legalised EAS are met, to the ongoing higher levels of illegal practices, to the incremental increase of such practices, both legal and illegal [3], and to concerns about how such legislation might affect the safeguarding and rights of vulnerable patient groups $[4,5]$.

This paper aims to examine and reflect on the way in which legal criteria are applied to patients with intellectual disabilities and/or autism spectrum disorder who request EAS in the Netherlands, the first country in the world to introduce EAS legislation. The authors of this paper are experts in the fields of intellectual disability and end-of-life care. They come from the UK and the Netherlands, two countries where ethical principles are translated into divergent legal frameworks with regards to EAS. The aim of this paper is not to present a common ethical view or to promote a particular side of the EAS argument, but to contribute to the EAS debate by discussing the implications, including the risks, for two particularly vulnerable patient groups, based on factual reports from a country where EAS is a legal possibility.

\section{Euthanasia and physician-assisted suicide (EAS) in the} Netherlands

In 2001 the Termination of Life on Request and Assisted Suicide Act ("the 2001 Act") was passed in the Netherlands, making it legally possible for physicians to terminate the life, or assist the suicide, of a patient provided that six 'due care' criteria have been met. These due care criteria include the requirement that the EAS request is voluntary and well-considered and that the patient experiences unbearable suffering without prospect of relief. All decisions by doctors to administer euthanasia or assist a patient's suicide must be reported to a regional review committee (Regionale Toetsingscommissie Euthanasie (RTE)) legally tasked with scrutinising after the event whether the decisions that were made met the due care criteria.

The 2001 Act requires the RTE to issue annual reports describing their findings. These annual reports are available on the RTE website (including English, French and German translations from 2010), along with further selected case summaries (in Dutch only) (www.euthanasie commissie.nl / https://english.euthanasiecommissie.nl). In 2015, the RTE published a Code of Practice which outlines the issues that the committees regard as relevant in performing their statutory task; this too is available on the RTE website, including an English translation. The Code of Practice gives guidance to physicians on assessing whether a patient meets the criteria for EAS. It acknowledges, for example, that 'unbearable suffering' is a subjective notion: what is bearable for one patient may be unbearable for another. It stipulates that the suffering must be 'palpable' to the physician and states that "the physician must therefore not only be able to empathise with the patient's situation, but also see it from the patient's point of view" [6] (p.14). The case summaries and annual reports are written in lay language. They are explicitly meant to give an impression of how the committees apply and interpret the due care criteria for euthanasia and physician-assisted suicide as set out in the Act, and as such, they serve as 'case law'. Additional file 1 gives an overview of the practice of EAS in the Netherlands, the due care criteria, and of the RTE.

It is important to note the factors that are not mentioned in the 2001 Act. There are no specified causes of suffering for which EAS is permitted, and the Act says nothing about the patient's life expectancy. In practice, life expectancy will often be limited, but the Act does not rule out granting an EAS request from a patient who may have many years to live [6]. In 2002 the Dutch Supreme Court passed a verdict in the Brongersma case (the physician-assisted suicide of an elderly gentleman who suffered immobility and loneliness, and was 'tired of life') that the unbearable nature of the patient's suffering, and the lack of prospect of improvement, must have a medical dimension [7]. From previous verdicts by the 
RTE, it is clear that the medical condition can be either somatic or psychiatric, and that an accumulation of conditions of old age can also be the cause of unbearable suffering without prospect of improvement. The law also makes it legally possible for patients who are no longer capable of expressing their will (including those with advanced dementia) to have EAS, as an advance euthanasia directive can replace a verbal EAS request. There have been proposals to extend the option of EAS to people who do not suffer on medical grounds but simply feel they have 'completed life'; in 2016, these proposals were investigated and rejected by parliament [8], but the societal debate and campaign continues. The total number of EAS notifications in 2016 was 6091, which accounts for $4 \%$ of all deaths in the Netherlands; of these, over 96\% were euthanasia and $3.5 \%$ were physician-assisted suicide [9].

\section{EAS for mental suffering}

The number of Dutch cases of EAS for psychiatric problems remains relatively small, but is rising steadily. There were 2 reported cases in 2010, 42 in 2013, and 60 in 2016. EAS for mental suffering has been fiercely debated. Arguments have focused on the difficulty of assessing the patient's subjective perception and complaints and on the challenges in assessing the patient's capacity of judgement, which may be impaired by psychiatric conditions such as severe depression [10-12]. Arguments in favour of including both mental and physical suffering as legally acceptable grounds for EAS focus on the fact that a key objective of such legislation is to relieve suffering. On what reasoning can it be offered to people with certain conditions (medical or otherwise) which cause suffering but not to others, given that psychological suffering may be as unbearable as physiological pain? It is worth noting that the reasons often given for EAS requests, even in cases of somatic conditions, are not so much a fear of pain: it is the functional limitations and dependence on others that many people find intolerable to such an extent that they would prefer to die [13].

\section{EAS, intellectual disability and autism spectrum disorder}

People fall within the definition of having an intellectual disability if they have a significantly reduced ability to understand new or complex information and to learn and apply new skills (impaired intelligence), resulting in a significantly reduced ability to cope independently (impaired adaptive and/or social functioning), which begins before adulthood, with a lasting effect on development [14]. Autism spectrum disorder is a complex and usually lifelong developmental disorder that can cause problems with thinking, feeling and language, characterised by persistent difficulties with social communication and social interaction [15]. Although autism spectrum disorders are common among people with intellectual disabilities, not all people with autistic spectrum disorder have an intellectual disability. Asperger's syndrome, for example, is a type of autism that is characterised by average or above-average intelligence.

We have found no papers to date that are focused on the implications of EAS legislation for people with an intellectual disability or autism spectrum disorder, but there have been discussions of the consequences for vulnerable patient groups. Frost et al. [4] assert that it is impossible for doctors to advise patients regarding the point at which their situation becomes less preferable to being dead. They argue that legalising assisted dying by attempting to establish an absolute right to bodily autonomy may undermine other individual and group rights, and that by creating one class of people for whom life is expendable, that particular view may be extended by society to all groups possessing such attributes (such as permanently disabled people). They fear that there would be a risk to the rights of such vulnerable groups in the form of society being less willing to provide for their care and support.

Krahn [5] reports on a debate by the Disability Section of the American Public Health Association on the meaning of policy on physician-assisted dying for people with disabilities, and concludes that this group bears a disproportionate share of the burden:

"Because aid in dying is used primarily to address loss of autonomy and not pain management, and because proponents argue that severe disability should warrant the right to end their life, this suggests a devaluing of a life lived with significant functional limitations...If society endorses the right of a person to seek physician assistance to end his or her life because of increasing loss of functional autonomy, what does that say about how our society values the lives of people who live with comparable limitations every day of their lives for years on end?" [5] (p.54)

This relates to the question whether the EAS criteria of 'unbearable suffering' can be applied to situations where suffering is caused by either lifelong or acquired disability, which is usually seen as a socially determined condition, not a medical one. A human rights argument is used by disability rights activists who fear that EAS stigmatises life with a disability and potentially discriminates against them. However, proponents of the right to die also cite a human rights argument [16]; this includes some disabled people who desire more control in the timing of their death [17].

The question whether people with intellectual disabilities and/or autism spectrum disorder need particular attention with regards to EAS is an important one - whether in relation to debates around putting in place EAS legislation, or 
in relation to EAS requests from vulnerable persons in jurisdictions that have such legislation in place. The principle that people with disabilities must not be treated differently on the basis of their disability is enshrined in the UN Convention on the Rights of Persons with Disabilities [18], firmly rejecting an approach where disability automatically disqualifies a person from making decisions. However, because of the serious and irrevocable nature of EAS, it could be argued that vulnerable people need special protection. There is thus a moral tension between people's right to autonomy on the one hand and the need to prevent harm on the other.

The Dutch due care criteria are intended to protect people from harm, whilst upholding their right to autonomy. This paper looks at how effective the due care criteria are in relation to people with intellectual disabilities and/or autism spectrum disorder. The Dutch RTE Code of Practice states:

"Notifications of cases of euthanasia involving patients with an intellectual disability are rare. There are cases where patients with a mild intellectual disability are capable of making a voluntary and well-considered request for euthanasia, and where all the other due care criteria are met. In these cases, particular attention must be paid to the patient's decisional competence with regard to a request for euthanasia." [6] (p.28)

The 2016 annual report includes a brief case summary of a man with an intellectual disability caused by tuberous sclerosis (case 2016-03), aimed at demonstrating that it is indeed possible to administer euthanasia to someone with an intellectual disability. Key to this was a capacity assessment by a physician who had specialised in the care of people with intellectual disabilities [9]. Assessing whether someone has the capacity needed to make decisions, which is crucial for the assessment of the due care criterion (a) 'voluntary and well-considered request', could be especially difficult if the patient has an intellectual disability and/or autism spectrum disorder. However, several of the other due care criteria could also present particular challenges for these patients, including criteria (b) assessment of a patient's suffering, (c) the provision of adequate information, (d) deciding together with the patient that there is no reasonable alternative, and (e) obtaining a second opinion from a physician who does not have a current or recent treatment relationship with the patient [6].

The questions we asked were: How do physicians and the Dutch regional euthanasia review committees operationalise the EAS due care criteria for patients who have an intellectual disability and/or autism spectrum disorder? What, if any, are the particular difficulties when the EAS due care criteria are applied to these patient groups?

\section{Methods}

During the 5 years between 2012 and 2016, the Dutch RTEs received a total of 25,930 notifications of EAS; case summaries of 416 of these are included (in Dutch) in a searchable database on the RTE website (www.euthanasie commissie.nl). There are no case summaries available from before 2012. The first and second authors (ITW and LC) are native Dutch speakers and fluent English speakers. ITW searched the RTE website for cases of EAS involving patients who had an intellectual disability and/or autism spectrum disorder, by using a range of relevant keywords ("verstandelijke/intellectuele beperking", "zwakbegaafd", "lage/verminderde intelligentie", "autisme"). This resulted in 11 case summaries. One was excluded because the text said the patient had been assessed for autism but was found not to have it; and one was excluded as it concerned a patient with dementia rather than an intellectual disability. The keyword 'cognitive disturbances' ('cognitieve stoornissen') led to 38 additional results, all of which were read and excluded, as they concerned patients with psychiatric conditions or dementia but not intellectual disabilities. The nine remaining case summaries were translated into English by ITW and read by all authors. They were analysed using directed content analysis [19] with pre-determined coding categories related to due care criteria (a) to (e) (see Additional file 1). The final due care criterion (f) relates to the drugs used to carry out the euthanasia and was reported using near-identical wording in each of the case summaries; this was excluded from our analysis. Because the number of cases was relatively small, no supportive software was used for the data analysis.

\section{Results}

The patients

Table 1 presents a summary and selected quotes with regards to the patients' stated characteristics, diagnosis, and due care criteria (a) to (e). There were six women and three men, with ages ranging from patients in their 30 s to a patient in her 90 s.

\section{Intellectual disability and/or autism spectrum disorder}

Six patients had an intellectual disability, although none of the case summaries describe the nature or extent of the intellectual disability, nor how it affected the patient's life. One woman (case 2014-83) was placed under guardianship and had a mentor who was present at the consultations with the physicians and who helped her register with the End of Life Clinic when her own physician declined to meet her euthanasia request. For one woman (case 2013-22), the intellectual disability and associated perceived lack of decision making capacity was noted by a psychiatrist; however, when the RTE asked the attending physician (who had carried out the euthanasia) for clarification, he said that the patient's low 


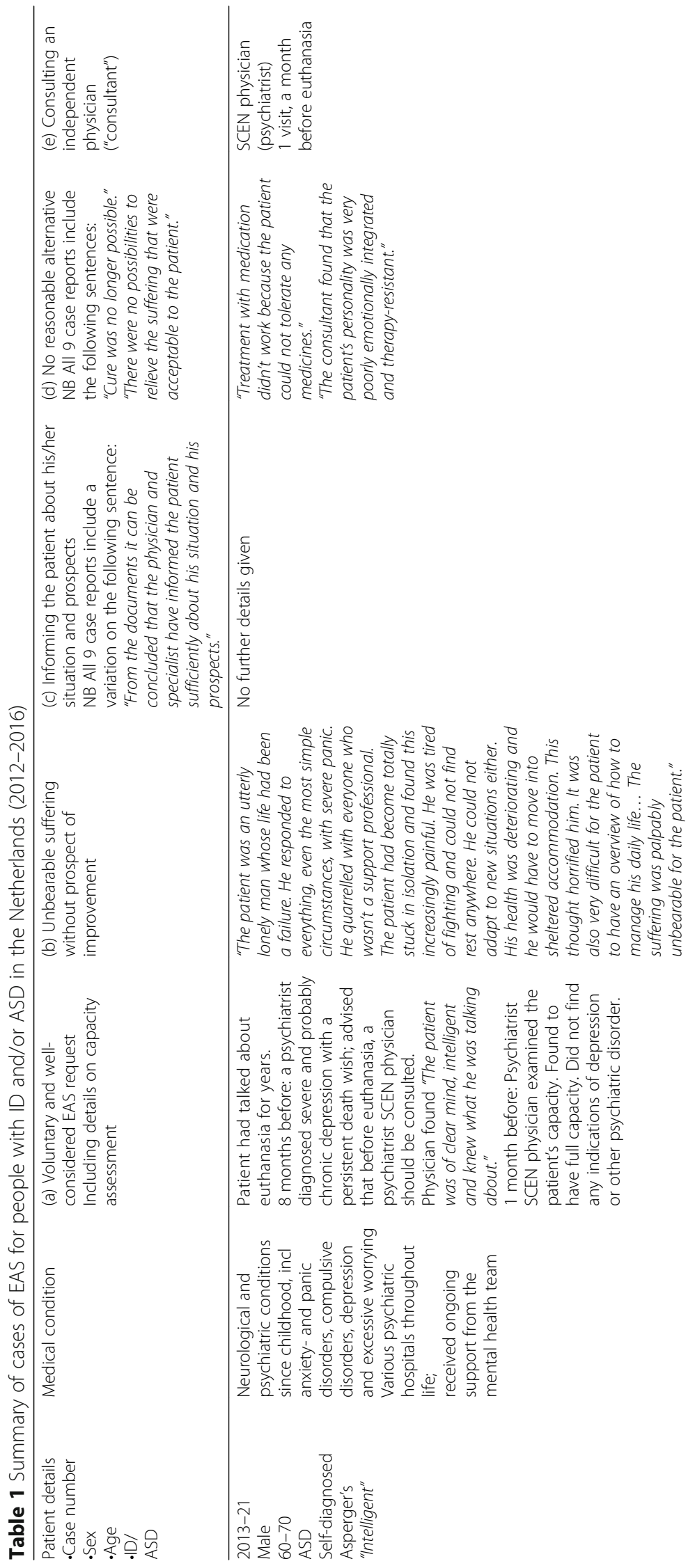

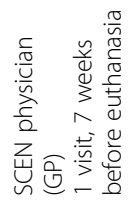

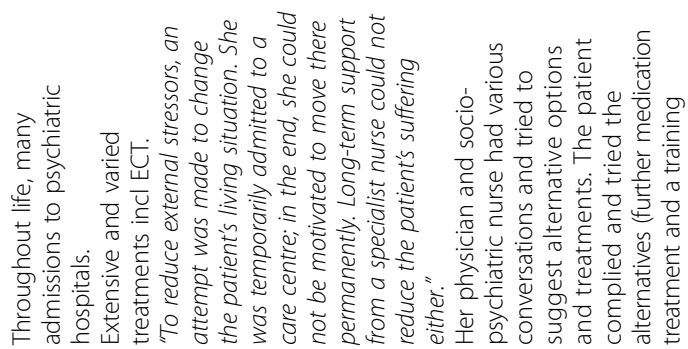

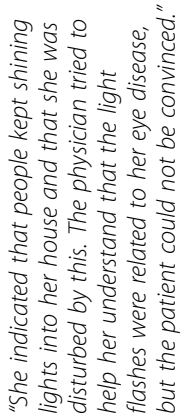

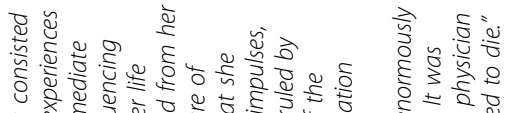

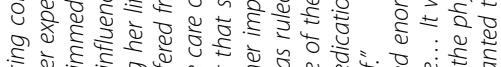

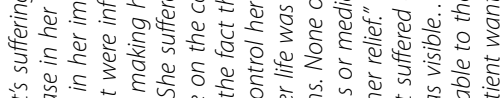

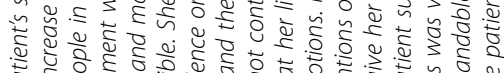

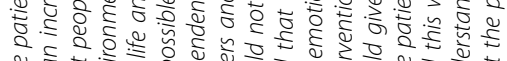

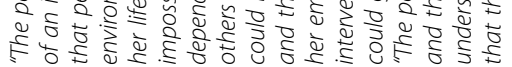

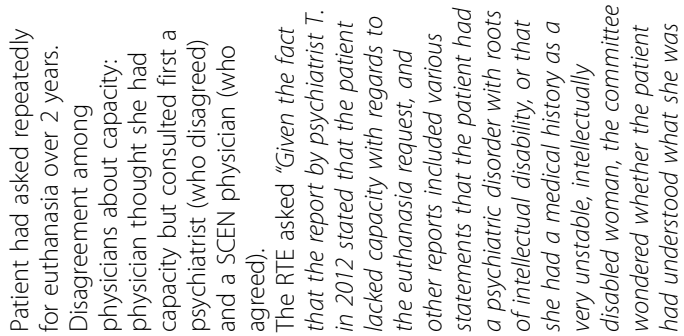

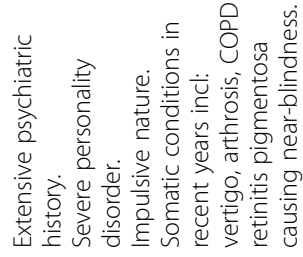

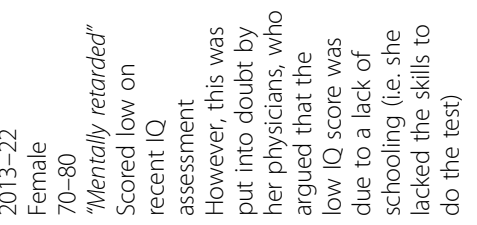




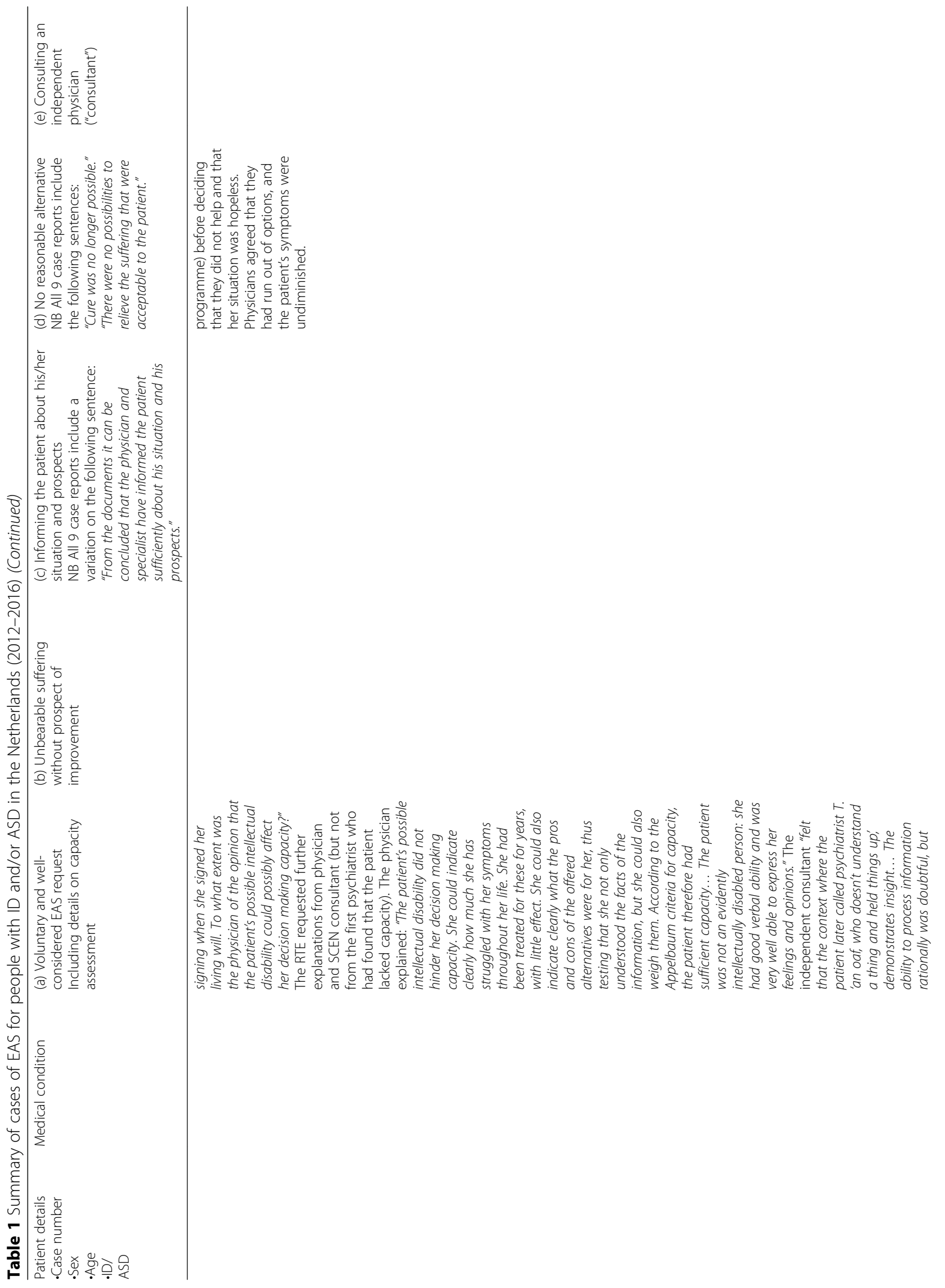



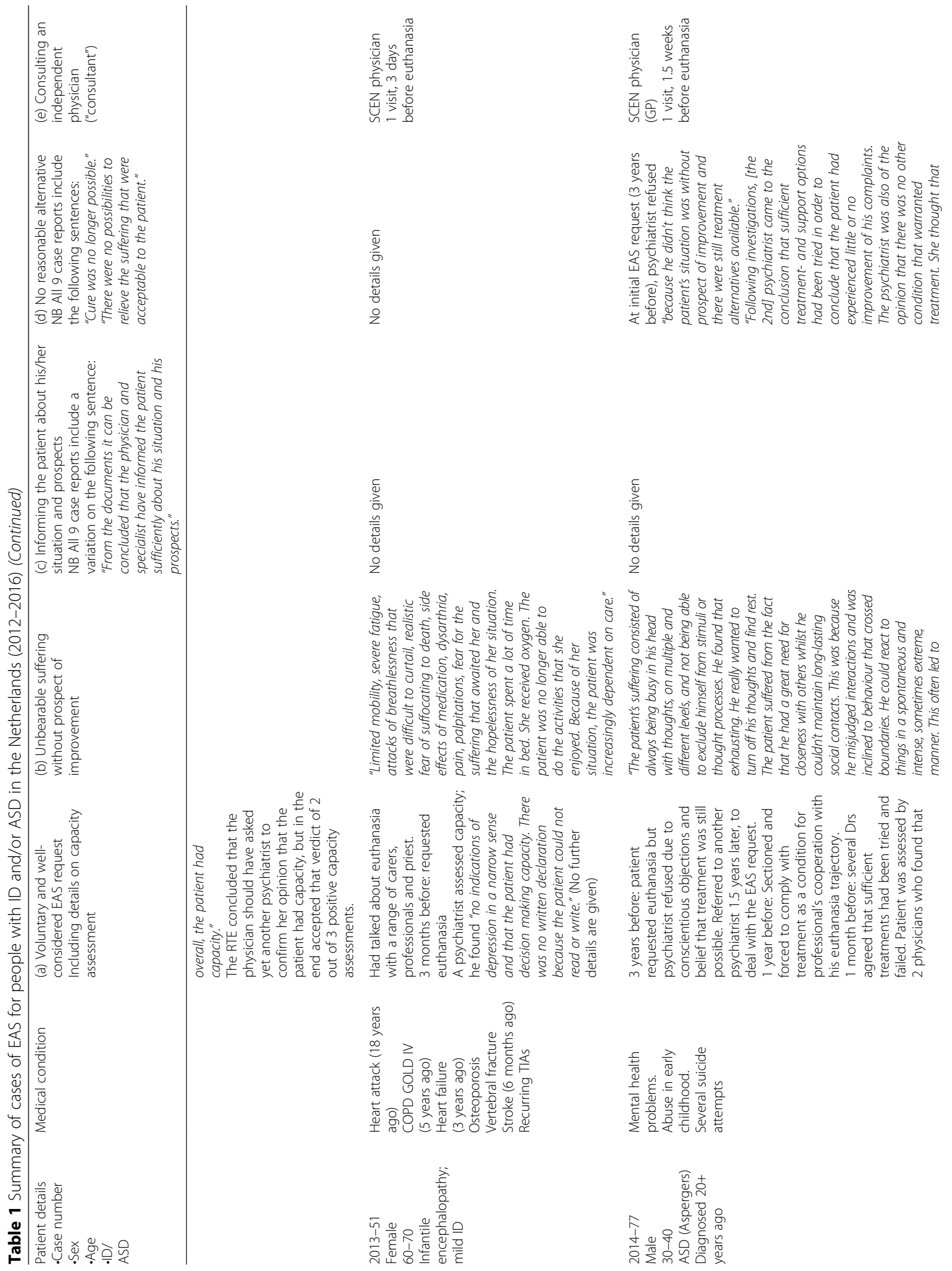


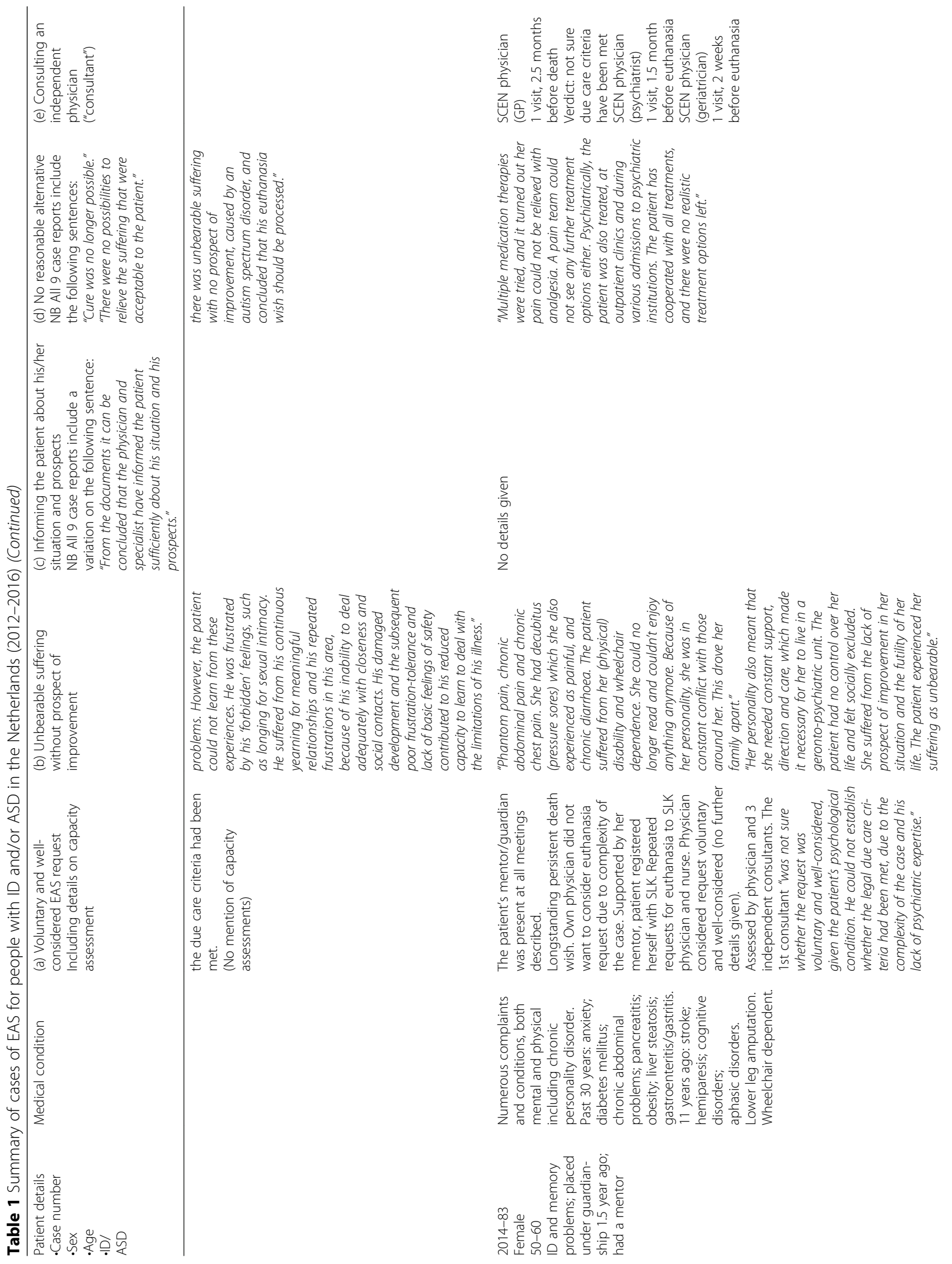




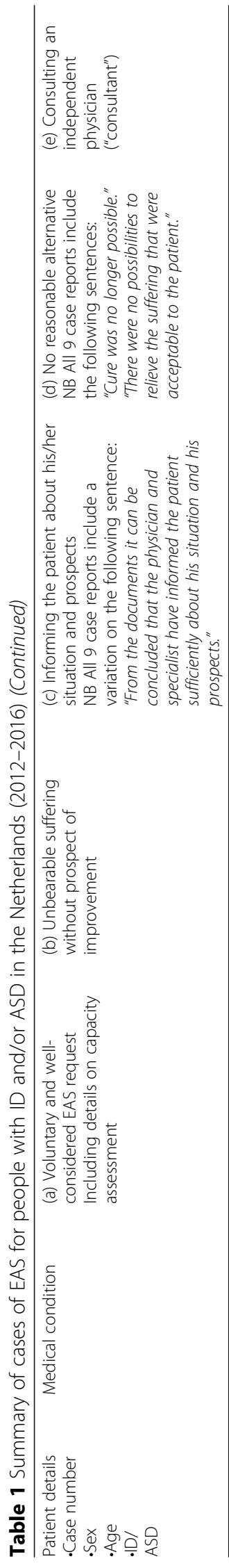

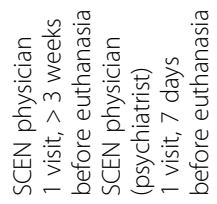

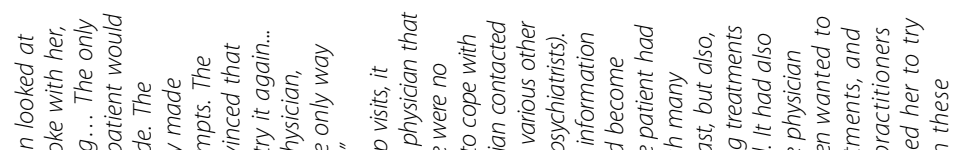
ई

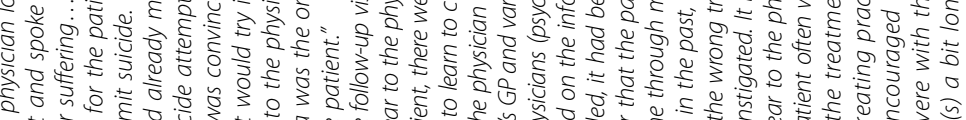

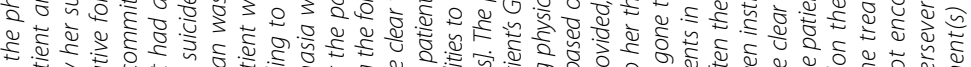

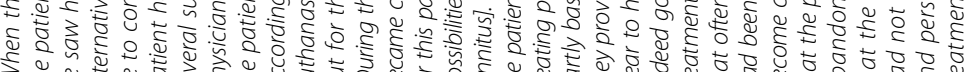

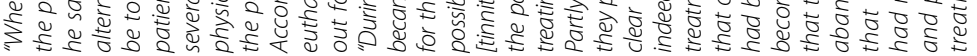

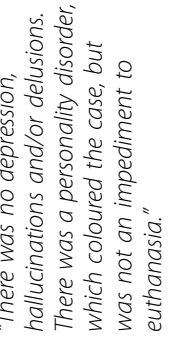

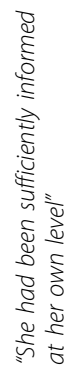

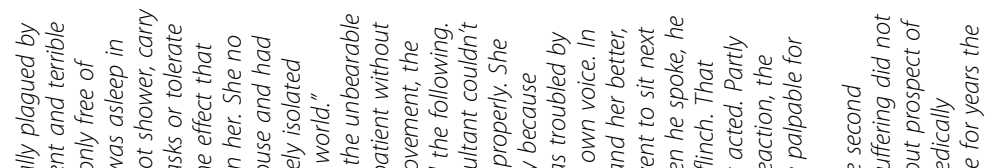

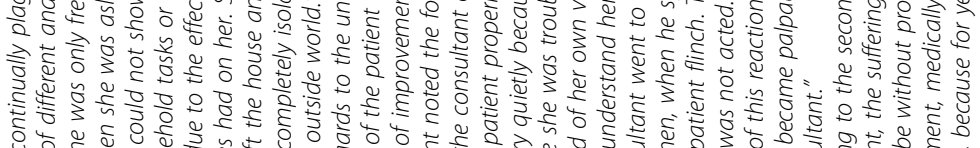

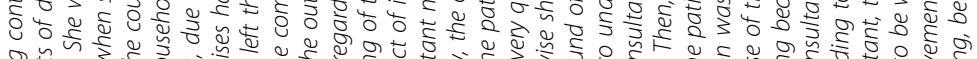

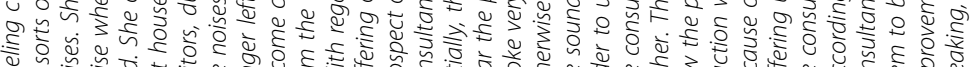

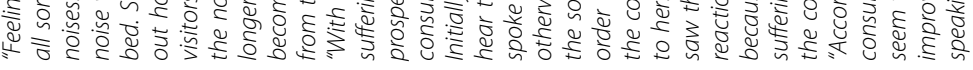

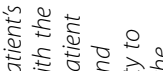
$+$

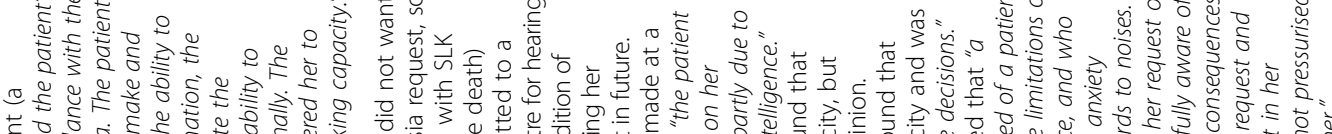

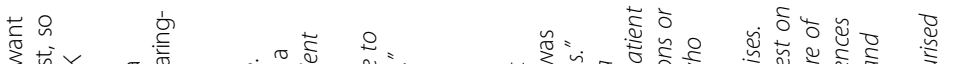

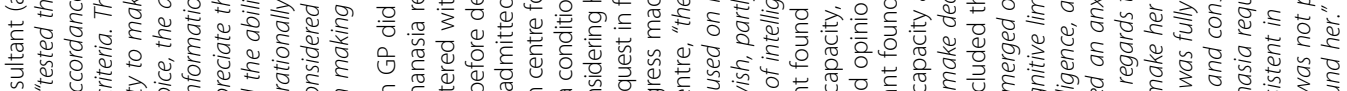

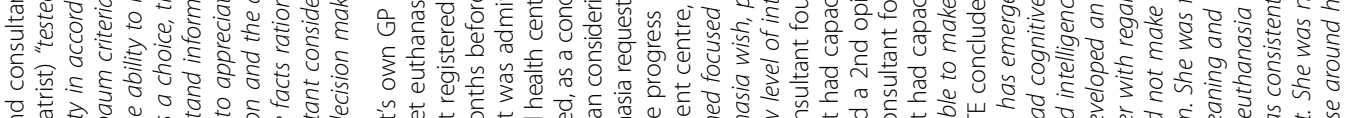

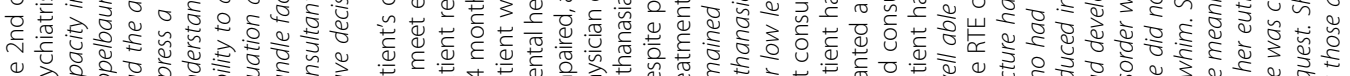

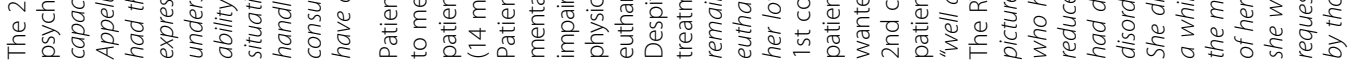

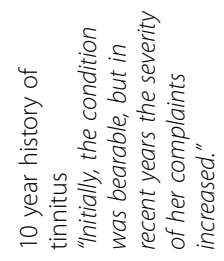

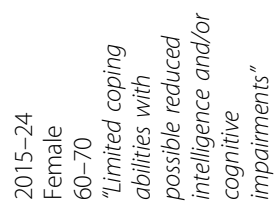




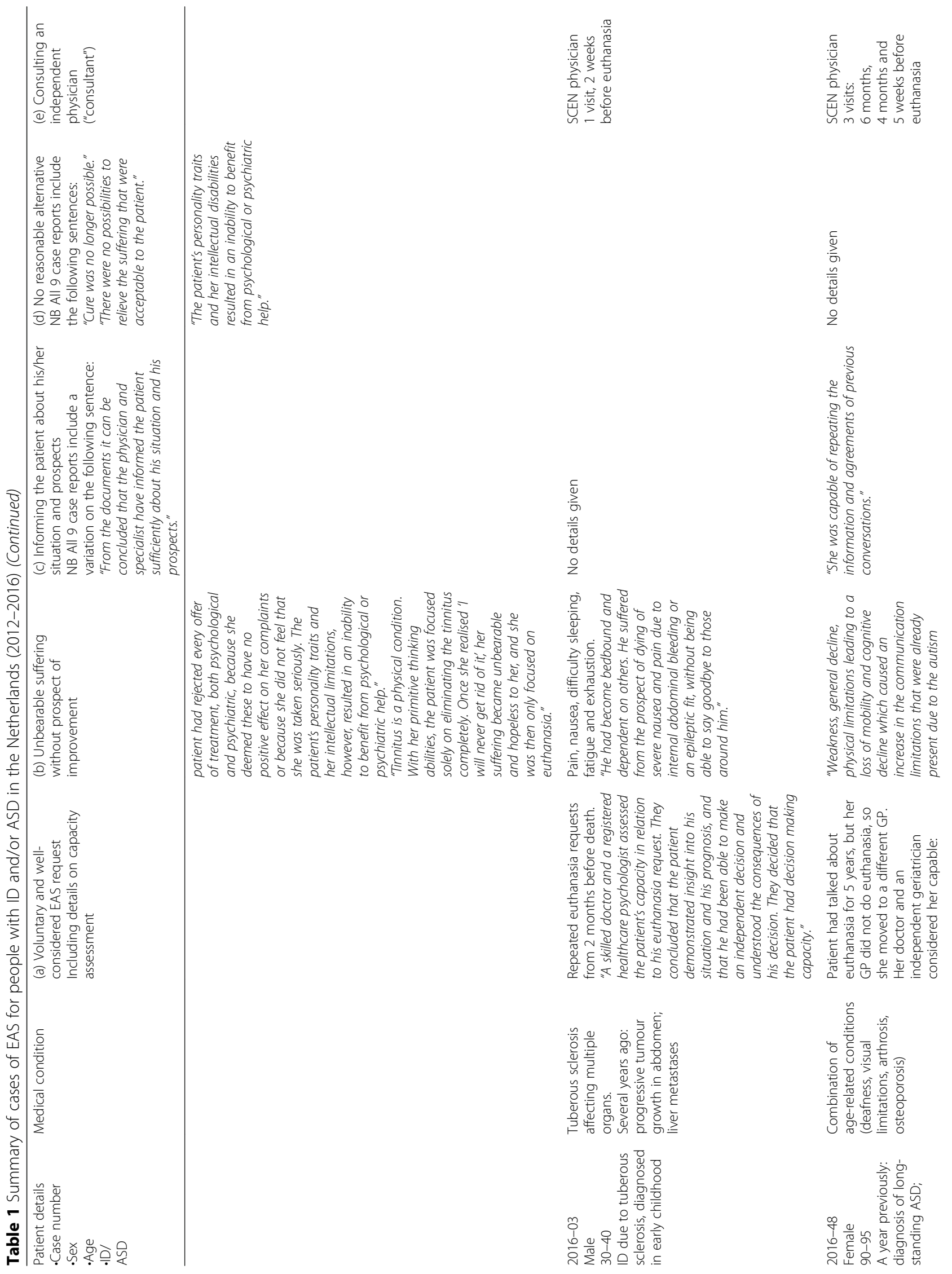




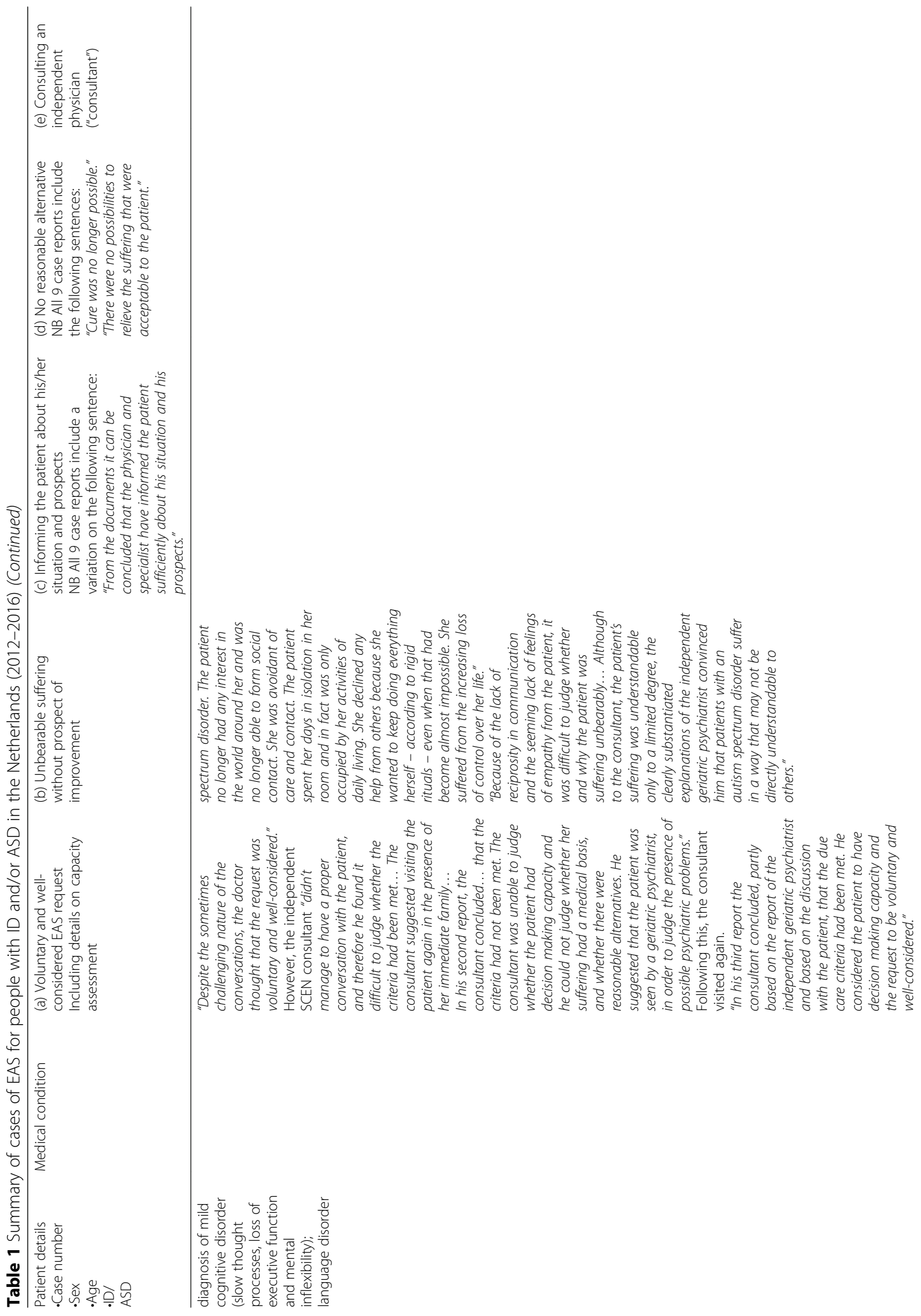




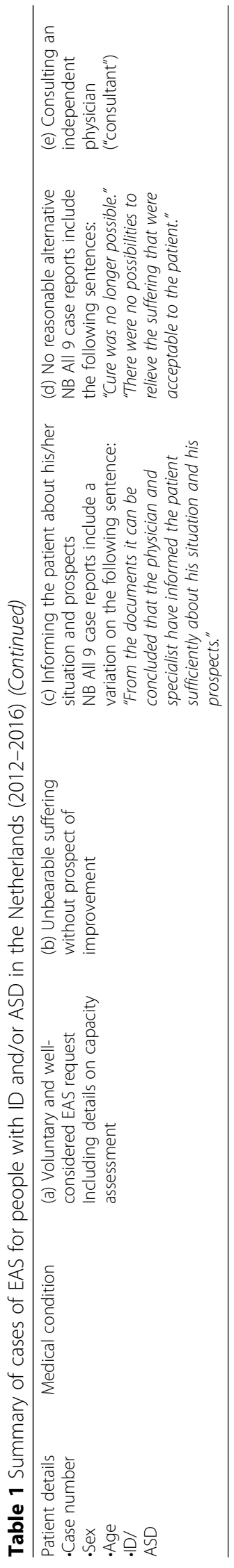

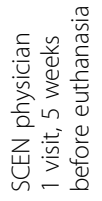

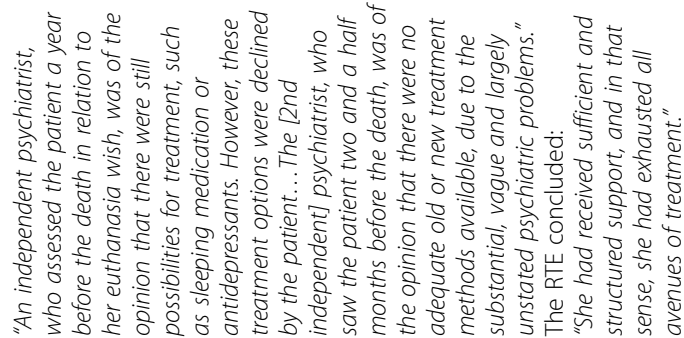

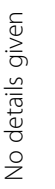

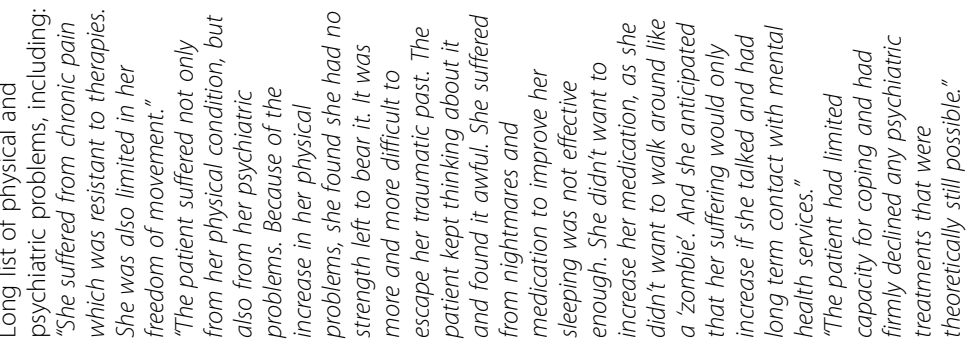

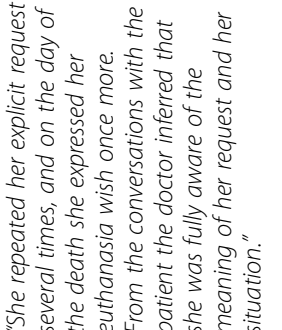

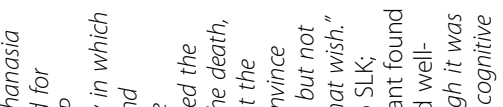

$\begin{array}{llll} & \\ 0\end{array}$

$\begin{array}{lll} & \\ 0\end{array}$

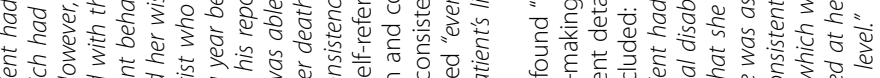

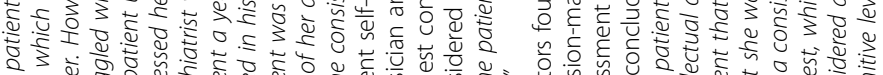

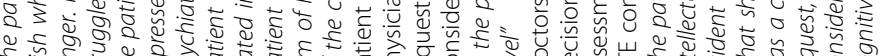

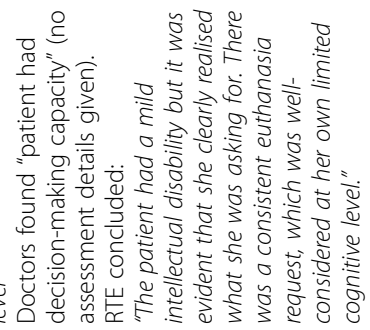

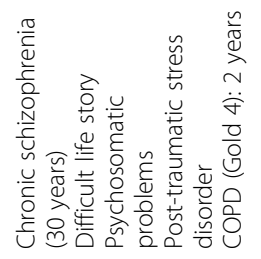

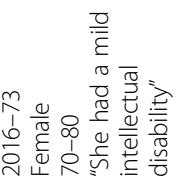


IQ score was probably due to a lack of schooling. Two men had Asperger's syndrome. One woman (case 201648) had an autism spectrum disorder; slowness of thought and mild cognitive disorder were also mentioned, but it is not clear whether this was due to old age, physical decline or intellectual disability.

\section{Social circumstances}

There was a fleeting reference to the patient's family in three case summaries (Case 2014-83: "Because of her personality, she was in constant conflict with those around her. This drove her family apart." Case 2015-24: "The patient's family responded positively to this possibility of admission [to a psychiatric unit]." Case 2016-48: The consultant "didn't manage to have a proper conversation with the patient, and therefore he found it difficult to judge whether the due care criteria had been met... The consultant suggested visiting the patient again in the presence of her immediate family." It was not reported whether this happened.)

None of the other case summaries contained any indication of the existence of family, friends or partners. A mentor was mentioned in three cases. One patient lived in a psychogeriatric unit and one lived alone; the other case summaries lacked information about the living situation, so it was unclear whether a patient lived alone, with family or others, or in a care setting. Previous admission to a psychiatric in-patient setting was mentioned in six cases. Information on other social circumstances was similarly sparse, although there were several references to a patient's loneliness and social isolation.

\section{Applying the due care criteria}

\section{(a) Voluntary and well-considered request}

The EAS request, usually to a patient's own GP, was initially refused in six cases. Three GPs "didn't do" EAS. In the other cases, the physician thought that the case was too complex or the due care criteria had not been met. These patients, whose request had been refused, then went to another physician or to the End of Life Clinic.

There was an emphasis in the Dutch case summaries on assessing the consistency of the patient's choice, with statements such as "she clearly realised what she was asking for" (case 2016-73). Capacity assessments were mentioned in eight case summaries, although five of those contained no detail beyond the fact that the patient was found to have decision-making capacity. In three cases, physicians disagreed or wanted a second opinion about the patient's decision-making capacity. The use of the Appelbaum criteria [20] (see Additional file 2) was mentioned in two cases. In one of these (case 2013-22), the physician concluded that the patient did not meet one of the Appelbaum criteria (the ability to process information rationally), but that she had "overall capacity". One consultant, who felt unable to assess capacity and found that the due care criteria had not been met (case 2016-48), later accepted the positive capacity assessment of an independent psychiatrist; no further explanations were given of how this conclusion was reached.

\section{(b) Unbearable suffering without prospect of improvement}

The case summaries all described the patients' 'unbearable suffering' in order to explain the EAS request. Two patients (cases 2013-51 and 2016-03) had progressive somatic conditions; the nature of their suffering was described in terms of their physical decline and increasing dependence.

Five had extensive, complex and longstanding psychiatric problems, including personality disorders, schizophrenia and trauma resulting from childhood abuse. Four of these had developed additional somatic conditions, reducing their ability to cope. Difficulty in accepting or coping with changes in circumstances was explicitly ascribed to the presence of an intellectual disability or autism spectrum disorder and judged to be a valid cause of unbearable suffering.

The physicians of a woman in her 90s, suffering from age-related conditions (case 2016-48), found it "difficult to judge whether the patient suffered unbearably" and found that "the patient's suffering was understandable only to a limited degree". Assessment by an independent psychiatrist was requested; the explanations of this psychiatrist "convinced the patient's physician that people with an autism spectrum disorder suffer in a way that may not be directly understandable to others". It was accepted that the patient's suffering was unbearable "by looking at suffering from the perspective of someone with autism. The loss of control... can cause unbearable suffering for an autistic person."

For two patients, for whom various psychiatric and somatic conditions were described, the stated suffering appeared to stem from characteristics of autism spectrum disorder itself, rather than from acquired medical conditions. One man (case 2013-21) was said to be unable to adapt to new situations and found it very difficult to have an overview of how to manage his daily life. For another, a man in his 30s (case 2014-77), who had an extensive psychiatric history, the suffering was vividly and strikingly described as being unable to maintain social contacts or have meaningful relationships. The case summary stated that his suffering was "caused by an autism spectrum disorder" and continued that "cure was no longer possible. The treatment was only palliative." The statement that "cure was no longer possible" seemed to be standard, as it 
appeared in all nine case summaries; the palliative nature of treatment was mentioned in seven cases.

\section{(c) Informing the patient about his prospects}

Each of the case reports included the identical statement that "the physician had informed the patient sufficiently about his/her situation and his/her prospects". However, there was no information about how the patients were helped to understand their situation, or whether any adjustments needed to be made to support understanding. One patient (case 2015-24) was said to have been "sufficiently informed at her own level". There is an indication in one case (2013-22) that the physician tried and failed to help the patient understand the nature of her symptoms (flashing lights due to eye disease).

\section{(d)Lack of a reasonable alternative}

Treatment alternatives were mostly described as having been tried and found to be ineffective. All case reports stated that "there were no possibilities to relieve the suffering that were acceptable to the patient". The key to this statement appeared to be "acceptable to the patient". In several cases, the physicians thought there might be alternatives to EAS. Complying with another treatment was a condition for entering the EAS trajectory in two cases; both failed to improve the patient's condition. In one case (2016-73) the psychiatrist who assessed the patient in relation to the EAS request felt that EAS was inappropriate as alternative treatments could be tried, but the patient refused. Another psychiatrist was then found who agreed that there were no treatment options left. Patient refusal or non-compliance was a common reason for physicians running out of options, leading them to agree that the situation had become hopeless. This includes a woman who suffered from tinnitus (case 2015-24); her EAS request stemmed from a refusal to cooperate with treatments that might enable her to live with the condition. Her sole focus on euthanasia rather than possible treatments was explained by her physicians as being due to her "primitive thinking abilities". Her physician "saw her suffering" and thought that, because none of the other choices being offered to relieve the suffering were acceptable to her, "euthanasia was the only way out for the patient".

\section{(e) Consulting at least one other independent physician}

An independent physician, often a psychiatrist, assessed whether due care criteria (a) to (d) had been fulfilled. In all cases, this was a SCEN (Support and Consultation on Euthanasia in the Netherlands) physician who had been specially trained to provide such consultation and give a written opinion. These consultants did not know the patient; he or she read the case notes and typically visited the patient once, between 5 weeks and 3 days before the euthanasia was carried out. A typical statement was "The psychiatrist spoke with the patient... he concluded, partly based on the conversation with the patient, that the due care criteria had been met" (case 2014-77). In one case (2016-48) the consultant visited the patient three times over six months, as he was not sure whether the due care criteria had been met. Two SCEN physicians were consulted in case 2015-24 and three in case 2014-83, also because of uncertainty about the due care criteria.

The RTEs accepted the physicians' assessments of patient suffering, prospects and capacity in all cases. Where there had been doubts or disagreements, they asked the physicians with the positive assessments of due care criteria (a) or (b) for further explanations, but not those with negative assessments.

\section{Discussion}

In a society where EAS is legalised and a clearly viable option in the eyes of a large proportion of the population, as is the case in the Netherlands (where currently around 1 in 25 deaths are through EAS [9]), there should be clear and compelling reasons if a person with an intellectual disability or autism spectrum disorder is to be denied this option.

Our findings are in line with those of Kim et al. [21] who reviewed 66 Dutch case summaries of patients receiving EAS for psychiatric conditions. In a discussion of capacity evaluations in these 66 cases, two of the cases we examined (2013-22 and 2014-83) are described in detail [12]. They conclude that

"the practice of EAS for psychiatric disorders involves complicated, suffering patients whose requests for EAS often require considerable physician judgement. The retrospective oversight system in the Netherlands generally defers to the judgements of the physicians who perform the EAS." [21] (p.367)

Dutch physicians thus carry significant responsibility in deciding whether or not a patient's EAS request can be met. Here we discuss the difficulties they face in applying the due care criteria to the situations of vulnerable patients.

\section{(a) Voluntary and well-considered EAS request}

The RTE Code of Practice 2015 states that "decisional competence means that the patient is able to understand relevant information about his situation and prognosis, consider any alternatives and assess the implications of his decision" [6] (p12). The RTE highlights the importance 
of careful capacity assessments if the patient has an intellectual disability [6]. The case summaries have shown how difficult such assessments can be, and it is therefore particularly unhelpful that so little detail is given about how the conclusion was reached that these patients had capacity.

Under Dutch legislation [22], as in many other jurisdictions including the UK [23], capacity is decision-specific. There is a presumption that capacity should be deemed to exist unless there is evidence to the contrary; in other words, the test for capacity involves disproving someone's competence for a particular decision. Dutch government guidance states that capacity assessments should be based primarily on a patient's ability to comprehend the decision, rather than on the outcome of the patient's decision, as focusing on the latter risks the assessor's norms and values being decisive. However, it goes on to explain that:

"This does not mean that the assessor must put aside his own norms and values completely. In dialogue between the assessor and the patient, their respective norms and values can influence each other; but in assessing decisional capacity, the assessor's norms and values must not be unilaterally decisive. However, the nature of a patient's intended decision can be a reason for assessing his decisional capacity." [22] (p.7, translated by ITW)

This guidance seems to recognise the perhaps difficultto-avoid fact that a physician's ideas about what is best for the patient may influence the patient's choices.

The most commonly used and influential model for assessing whether a patient has the capacity to exercise autonomy in making healthcare choices is the MacArthur model, which consists of four abilities (also known as the "Appelbaum criteria"): to understand the illness and treatment-related information; to appreciate the significance of that information; to weigh up options using reasoning and logic; and to communicate a choice [20] (see Additional file 2). The Appelbaum criteria were referred to by Dutch physicians and the RTE as their model for capacity assessments. The use of this model for EAS decisions is not without its difficulties. Whilst impairment of decision-making capacity lies on a continuum, the judgment of decision-making capacity is an all-or-nothing concept (either the patient has capacity to take a particular decision, or he doesn't). Where on the continuum the cut-off point for competence lies, is therefore a matter of physician judgement. Appelbaum [24] has argued that the stringency of capacity tests should vary directly with the seriousness of the likely consequences of the patient's decisions. In the reported case summaries, it appears that the bar is not set high. In one case, the physician stated explicitly that a patient did not have all four Appelbaum abilities, but she was still deemed to be competent. This "lower threshold view" was also noted by Doernsberg et al. [12] in their review of capacity evaluations of psychiatric patients requesting EAS in the Netherlands. However, for decisions involving EAS, applying capacity laws and guidance is challenging. Legislation and guidance governing capacity assessments have not been written specifically for assessment of EAS requests; indeed, the Mental Capacity Act 2005 (England and Wales) [25] specifically states at Section 62 that nothing in the Act affects the law relating to assisting suicide. Wide variations and inconsistencies have been reported in the way mental capacity in patients requesting hastened death is conceptualised, but many consider that EAS should only be open to those with a high degree of mental capacity to make such a request [11]. In other words, for a life-or-death decision such as EAS, the bar should be set high, with patients meeting all aspects of stringent capacity assessments. Whether the MacArthur model is in fact appropriate for such assessment is open to debate and requires a comparative prospective research study. The model has been criticised for its focus on cognition, understanding and reasoning, ignoring the importance of emotions, values, biographical and context-specific factors [26-29]. A study by Tan et al. [28] showed that competence to refuse treatment may be compromised in patients with anorexia nervosa because of their difficulties with thought processing and changes in values, which was not captured by the standardised tests for competence. Breden and Vollmann [26] argue that in reality, patients often base a preferred choice on emotions, values or intuitive factors rather than on a rational analysis of all the options. This debate is important and may well lead to future changes in the way decision-making capacity is conceptualised and assessed, but at present, the MacArthur model is reflected in legal frameworks as well as guidance to Dutch physicians. Because of the complexities of capacity assessments and the judgement required of physicians, even within the seemingly clear Appelbaum criteria, it is especially important that the specifics of such assessments are described with greater transparency than we have found within the case summaries. Stringent capacity testing and a high bar for decisionmaking capacity, under the current model, would mean that the patient has all four Appelbaum abilities. We could not find evidence of such stringent testing in the Dutch case summaries. Most contained no detail of how the Appelbaum criteria were operationalised.

The RTE reports put a heavy emphasis on the consistent or repeated nature of an EAS request, but for people with an intellectual disability, the difficulties with decisionmaking are more commonly in the area of 'appreciating the significance of the information' or 'reasoning with the 
information and weighing up treatment options' (see Additional file 2). An example of how a consistent treatment refusal can be wrongly seen as a competent and autonomous decision is given in a UK study of patient safety issues, where a senior hospital consultant initially thought a patient with intellectual disabilities was being clear and consistent in his treatment refusal:

"[The patient] had cancer and needed surgery. I didn't realise that he didn't have the capacity to say 'no' to the operation. He didn't want the operation, and I just thought that was that." [30] (p.98)

It wasn't until this patient was seen by the hospital's intellectual disability nurse specialist, who found that the patient did not fully appreciate the consequences of his decision, that he was found to lack capacity; the patient, who would have died without surgery, had the operation after all, following a 'best interest' decision.

A persistent request does not necessarily imply capacity; it might even be indicative of a lack of capacity, if the patient's intellectual disability leads to difficulties in considering or weighing up alternatives. In case 2015-24 (the woman with tinnitus), the consistency of the patient's EAS request took precedence over her ability to consider alternatives, which the physicians agreed was impaired due to her low level of intelligence. This was not helped by the fact that "often the wrong treatments had been instigated" and "practitioners had not encouraged her to try and persevere with these treatment(s) a bit longer". If stringent capacity assessment criteria were to be applied in this case, it may well be that the patient's inability to appreciate the significance of the information in relation to her own situation, and to weigh up treatment options, would render her incapable to make an EAS decision, however persistent her EAS request. In case 2013-22, the patient interpreted light flashes related to her eye disease as "people shining lights into her house" and was disturbed by this; she "could not be convinced" by the physician's efforts to help her understand the cause of her symptoms. Under stringent capacity testing, such inability to understand the nature of her condition could have led to the conclusion that the patient lacked decisional capacity. As the Dutch government guidance states:

"In assessing whether the patient understands the nature of his health condition, one aspect that must be checked is whether he can see the relevant causal links, or conversely, whether he ascribes his health condition to a cause other than the 'objectively' determined one. A lack of insight into his condition is a factor that can be important in assessing decisional capacity." [22] (p.12, translated by ITW)
It is evident from the RTE verdicts that it does not require patients to meet all four Appelbaum criteria. The difficulties many people with intellectual disabilities have in rationally manipulating information with regard to their situation, the consequences of their decision and the possible alternatives make them particularly vulnerable when the bar for capacity assessment is not set high. Of all four Appelbaum criteria, appreciation ability is undoubtedly the most difficult to understand and measure. This conclusion was also reached in a systematic review of decision-making capacity of patients with depression, which found that appreciation of information was the ability that was most impaired, but difficult to measure within standard capacity tests [29].

Making a "voluntary and well-considered request" is closely related to the concept of autonomy. Autonomy in decision-making is complex for people with intellectual disabilities and not easily achieved. Whether a person is able to have a high level of self-determination is not necessarily dependent on their intellectual ability. A study of 301 adults with intellectual disabilities found that experience and opportunities to make everyday choices contributed significantly to greater self-determination and autonomy; intellectual capacity, on the other hand, was not a significant factor [31]. People with intellectual disabilities generally have less experience of and control over major decisions that affect their lives than those without intellectual disabilities [32], and therefore may lack the necessary skills in making life-changing decisions.

A recognition that people with cognitive conditions may need not only highly skilled capacity assessments but also robust support in the decision-making process is not clearly addressed within the Dutch case summaries. The presence of a 'mentor' at patient-physician meetings was mentioned in two case summaries, but family was notably absent. It may be that family and carers were involved but that this was not reported in the case summaries; or that the reporting physicians wanted to be sure that the patient was not under undue influence of family or carers ('voluntary request'). It seems, however, that for vulnerable patient groups, the perspectives of those in the person's social circle can be invaluable. In the UK, inquiries into health and social care provision for people with an intellectual disability have found consistently that including and listening to their family and carers is important in ensuring patient safety $[33,34]$. The guidelines for testing impairment under the Oregon Act [35] include the recommendation to consult, where possible and with the patient's consent, the patient's significant others about their views on the patient's competence and the patient's decision. Similarly, the Dutch government guidance on capacity assessments includes the statement that "the decision about capacity is often difficult and should be discussed with the various professionals and carers involved... this is particularly important for serious 
decisions" [22]. We found no evidence in the case reports that physicians included the perspectives of family and carers who knew the patient well.

\section{(b) Unbearable suffering without prospect of improvement}

Under the Dutch EAS system, it is up to the physician to decide whether the patient's suffering is indeed unbearable; this is then verified by the independent consultant. In the 2016 annual report, it is explained that the review committees

"do not re-examine the same issues as the physician who made the original decision. The RTE cannot do this, as the patient is no longer alive." [36] (p.24)

The RTE therefore scrutinises whether or not the physician could have reasonably come to a conclusion about the degree of suffering, but does not decree whether the physician's verdict is correct. This places the responsibility for assessing suffering solely on the shoulders of physicians. It is important to remember the gravity of the physicians' decision: in agreeing that suffering is unbearable and without prospect of improvement, they ultimately agree that it is better for the patient to be dead than to live.

There are obvious difficulties with implementing this criterion. Suffering is a deeply subjective experience, and it could be argued that no person can ever truly understand the experience of someone else's suffering, nor assess whether such suffering is severe enough to make the patient's life not worth living [37]. Cormack and Fléchais [38] point out that suffering needs to be interpreted in the context of the patient's personality structure, coping mechanisms and psychosocial environment, and argue that the Dutch requirement of suffering being 'palpable' to doctors raises concerns about counter-transference. The word 'palpable' is a perhaps inadequate translation from the Dutch 'invoelbaar, which implies that the physician needs to 'feel' or 'imagine' their patient's suffering, from the patient's perspective. The difficulties with this requirement are clear from those case reports where physicians struggled to understand the patient's perspective. Case 2016-48 (a woman with autism spectrum disorder) is a striking example. The physician visited the patient several times but was unable to understand the patient's view of her own suffering. He trusted a psychiatrist who told him that the experience of suffering is different for people with autism spectrum disorder. A physician's ability to empathise and 'feel' his patient's suffering is a guideline specified in the RTE Code of Practice [6], but it seems that because of the patient's specific disabilities, it was suggested that this was not possible. Physicians' acceptance that the suffering of patients with particular conditions may not be obvious to them could have the worrying implication that for people with some conditions or disabilities, a different (lower) standard for judging the severity of the suffering is accepted.

It has been made legally clear that a somatic or psychiatric medical condition must be the cause of the suffering that leads to the EAS request, but there is a lack of clarity around the question whether lifelong disability would qualify as a reason for EAS. If the answer is 'yes', the implications for people with disabilities could be very serious. In this context, it is of concern that for several of the patients', suffering was described in terms of their lifelong condition, rather than their psychiatric illness (see, for example, cases 2013-21, 2013-22 and 2014-77). Autism spectrum disorders and intellectual disability, with concomitant difficulties with social communication and relationships, could make it more difficult for patients to cope with the changes that come with ill health and ageing, or to weigh information, or to understand and accept possible alternatives. In the case summaries, the term 'suffering' was used to describe the normal variations in behaviour and perceptions seen in people with autism spectrum disorders which are an inherent part of the person. There were no explanations of how a lifelong condition such as autism spectrum disorder could be seen as "no longer" curable, nor how it might be treated palliatively. Statements about the lack of prospect of improvement, such as "intractable symptoms", "refractory to treatment" and "palliative treatment", are meaningless in the context of lifelong disability. This raises the prospect of diagnostic overshadowing, where there is a negative bias impacting on a clinician's judgement regarding co-occurring conditions in people with an intellectual disability or mental health condition, and symptoms due to a specific condition are attributed to another [39].

It seems clear from the Dutch case summaries that the patients were indeed suffering, and that they viewed their suffering as unbearable. When suffering is the result of a progressive medical condition, its assessment may be relatively straightforward. It is not surprising, perhaps, that case 2016-03 (a patient with an advanced tumour) is highlighted in the RTE annual report as an example of someone with intellectual disabilities who could choose EAS. Difficulties arise when the suffering, or the fact that the suffering cannot be relieved, is related to the nature of autism spectrum disorder or intellectual disability itself - as was the case for those who were highly dependent, had difficulties with social functioning, difficulties in coping with social circumstances, or a tendency not to cooperate with treatments.

Assessing the nature of suffering is a key question and has significance for disabled people, whether intellectual or otherwise. As we have seen, EAS requests are often based not on pain but on loss of dignity and autonomy. 
An unintended consequence of this rationale for EAS is to imply that lives lived with disability must be undignified, and that disabled people must experience suffering, despite assertions to the contrary by people living with long term disability [40]. Numerous reports in recent years have suggested that the lives of people with an intellectual disability are valued less across society, and that their short life expectancy results from inappropriate value-laden decision-making by healthcare professionals [30, 41, 42].

\section{(c) Informing the patient about his/her situation and prospects}

All patients need adequate information, but informing patients with intellectual disabilities may require considerable effort. It is crucial that the information is given in a format that the patient can understand, if patients with intellectual disabilities are to be properly supported to make decisions of such a serious nature. Even people with mild intellectual disabilities, who are recognised as being capable of making independent and autonomous decisions in some circumstances, may require information presented clearly in pictures or other reasonable adjustments in order to be able to fully understand and appreciate their situation. The lack of detail about how patients were informed about their situation and prospects makes it very difficult to understand how physicians have done this, or what expert assistance they need in the future.

\section{(d)No reasonable alternative}

The key challenge in relation to this due care criterion is that the conclusion must be reached by the physician together with the patient. This implies a level of partnership working of which many people with intellectual disabilities have little experience during their lifetime, making this a difficult criterion to implement. Partnership working and 'shared decision-making' are important in achieving patient autonomy and patient-centred care. It requires an excellent relationship between the physician and the patient. For people with intellectual disabilities and/or autism spectrum disorder, especially those who also have longstanding psychiatric problems, building such relationships is likely to require time, and therefore, applying the usual standards and timeframes for EAS trajectories may put vulnerable patient groups at a disadvantage, or even at risk. In several cases, especially those where the patient's own physician did not want to enter the EAS trajectory, the relationship between the patient and the physician carrying out the euthanasia was fairly recent. Furthermore, several case reports seem to imply that there were frictions between the physicians and patients, especially around the question whether further treatments were possible and reasonable. The patient who called her psychiatrist "an oaf who doesn't understand a thing" is an example of this (case 2013-22). It is difficult to see how an assessment of the patient's prospects can be made, together with the patient, in such complex circumstances.

\section{(e) Consulting at least one other independent physician}

As we have discussed above, assessing capacity and supporting autonomy outside an ongoing relationship with the patient can be problematic for people with intellectual disabilities, and these problems will be magnified if there are also mental health issues. It appears, therefore, that the requirement of a second opinion from an independent consultant (responsible for assessing whether the due care criteria had been met) may not be appropriate for people with cognitive conditions. It will often be too difficult to gain sufficient understanding of the patient and come to a fully informed view in just one meeting, no matter how carefully the consultant has studied all the case notes. It could be argued that it is difficult to assess any patient's request in one meeting, whether they have a disability or not, but it seems that people who have difficulty with communicating and relating to others are at a particular disadvantage.

\section{Limitations}

The most obvious limitation is that the case summaries are unlikely to tell the whole story. They are rather brief, with a frustrating amount of 'standard text' that sometimes fails to convey the individual nature of each situation. It may well be, for example, that family and carers were involved or that capacity assessments were far more extensive than was reported, but we could only base our assessment on what was written in the case summaries. It was striking that much illuminating detail was included in those case summaries where physicians had been asked by the RTE to give further explanations. It would be highly valuable to conduct in-depth interview-based research with physicians, families and carers who have been involved with EAS for patients with autism spectrum disorder or intellectual disabilities; this would provide crucial further insight into the patients' character, life story, social circumstances, important relationships, and crucially, the assessment of the due care criteria. It is possible that the concerns we have highlighted could be dismissed if the full facts of the cases were known. However, as Doernberg et al. [12] point out, since these summaries are meant to act as 'case law', not including extensive capacity discussions leads to the conclusion that the RTEs do not seem to expect high levels of scrutiny from physicians, nor a high threshold for capacity. 
It was not the aim of this paper to establish how prevalent EAS is for people with autism spectrum disorder or intellectual disabilities, and we are unable to conclude how often such cases arise. We found nine relevant case summaries out of 416 (2.2\%), which is roughly in line with the prevalence of intellectual disabilities among the population. However, those 416 published summaries represent only $1.6 \%$ of the total number of EAS cases over the 5 year period. It may be that the other $98.4 \%$ are more straightforward and less likely to involve such complex situations; on the other hand, it is also possible that intellectual disability is under-reported. In several of the case reports, the presence of "mild intellectual disability" was only mentioned in passing, in a description of the patient's medical history. It is also possible that many physicians do exercise extreme caution when a patient with an intellectual disability or autism spectrum disorder requests EAS, as indicated by the fact that two thirds of the reviewed cases had their initial EAS request refused. A study of outcomes of the 645 EAS requests to the End of Life Clinic during its first year (2012) found that about half such requests were refused. Factors associated with a request being rejected included being single, a psychological condition, and having loneliness or loss of mental capacity [43]. The lack of information on prevalence does not detract from the aim of this paper, however, which was to examine how the EAS due care criteria are (and can be) applied in these cases.

\section{Conclusion}

This paper tried to answer the question whether there are any particular difficulties in applying the Dutch due care criteria for EAS to patients with intellectual disabilities and/or autism spectrum disorders. Following the examination of the Dutch case reports, we conclude that the safeguards, in the form of legal due care criteria, are not easily applied to people with intellectual disabilities or autism spectrum disorder, and that the usual standards could in fact have the unintended effect of leaving vulnerable patients at risk. For disabled citizens to have equal rights (including the right to EAS in jurisdictions where this is a legal option), there must be 'reasonable adjustments' in place to ensure that the standard procedures do not leave them at a disadvantage.

Much attention has been focused on the importance of capacity assessments. The RTE Code of Practice [6] and 2016 Annual Report [9] have stipulated that EAS for people with intellectual disabilities is possible, provided that specific attention is paid to the assessment of decision making capacity. From the literature and our examination of nine case reports published on the RTE website, we conclude that assessment of capacity can be extremely difficult people with intellectual disabilities, however mild. It requires a high level of expertise and an intimate knowledge of the patient. There are specialist intellectual disability physicians in the Netherlands, but there was evidence of involvement of such a specialist in only one of the cases (2016-03). We would suggest that a specialist intellectual disability physician should be involved in all cases where someone with an intellectual disability requests EAS, and that all physicians involved in capacity assessments of patients with intellectual disabilities or autism spectrum disorder (including those offering a second opinion) must have enhanced training in this area. The currently used Appelbaum criteria for capacity assessments are not without their critics. The way in which these criteria are operationalised for people requesting EAS, and the question whether these criteria are in fact the most adequate or sufficient, needs urgent further investigation. To what extent the criterion of appreciating information is able to cover the complexities, emotions and values associated with making an EAS decision needs further clarification and debate. This is particularly pertinent for people with intellectual disabilities and/or autism spectrum disorders, but may also be highly relevant to patients with mental health problems or dementia.

The challenges in applying the EAS due care criteria to people with intellectual disabilities or autism spectrum disorder go well beyond capacity assessments, however. We are particularly concerned about the implications of the difficulties in assessing suffering in people with intellectual disabilities or autism spectrum disorder. Dependency, functional limitations and difficulties with integration in society are often part of conditions which these groups of people live with all their lives. The Dutch cases raise the possibility that the bar for assessment of intractable suffering is set lower for people with an intellectual disability or autism spectrum disorder than for the general population, by considering their long term disability as a medical rather than a social condition. We found no evidence of safeguards against the influence of the physicians' own subjective value judgements when considering EAS decision, nor of processes designed to guard against transference of the physicians' own values and prejudices. We suggest that it is important for physicians to be aware of, and articulate, their criteria for judging the patient's suffering; and for the people in the patient's circle of family and carers to be included in the process, and their opinions to be taken into consideration. We also suggest that an important 'reasonable adjustment' for patients with intellectual disabilities and/or autism spectrum disorder is an extension of the usual timeframes for EAS trajectories. Such an extended timeframe can help all physicians involved (including those required to give an independent opinion) to take the time to build a relationship of trust with the patient.

We align ourselves to the aim of the EAPC to promote the availability of the best possible palliative care for vulnerable people, including people with intellectual disabilities, in accordance with current professional opinion 
(including those of physicians, ethicists and lawyers) in each country. It has been recognised that people with intellectual disabilities need special attention to ensure equitable palliative care, as they have specific vulnerabilities that make it much more difficult to assess, interpret and meet their needs [44].

Within the Dutch system, we urge particular caution in cases of EAS requests from people with intellectual disabilities and/or autism spectrum disorder, with the onus on both physicians and the RTE to demonstrate much more clearly how all due care criteria were met. We suggest that there should be 'reasonable adjustments' to act as additional safeguards for vulnerable and disabled patients. Helping someone to die is such a serious and irreversible decision that if there is any doubt or uncertainty, even if only from one physician, we suggest that physicians should err on the side of refusal; and that if the EAS is subsequently carried out, the RTE process should include a review of the opinion of physicians who did not think the due care criteria were met. Looking at the international implications, we suggest that any plans to introduce or adapt EAS legislation should include a very careful assessment of whether such legislation includes sufficient safeguards to protect vulnerable patient groups.

Widening the implications even further, we speculate that many of the challenges highlighted in this paper could also be relevant to patients in the general population, and that they are simply more pronounced or extreme for vulnerable patient groups. It is quite possible that people with intellectual disabilities are like the canary in the coal mine, among the first to come up against issues that turn out to be issues for everyone. It may well be that the ability to use rationality and logic when weighing up the EAS option, and thus decisionmaking capacity in accordance with standard capacity tests, is impaired in most people affected by the emotional turmoil of terminal illness or suffering caused by chronic conditions. Perhaps the difficulties of physicians to appreciate suffering of patients with intellectual disabilities or autism spectrum disorders is in fact indicative of the difficulties in putting themselves into anyone's shoes. We have argued that people with intellectual disabilities who request EAS need particular attention and stringent assessments in order to protect them from harm. The question whether the Dutch due care criteria act as sufficient and effective safeguards for any patient, or whether assessments should perhaps be more stringent for all patients, would need further investigation and is beyond the scope of this paper. If more stringency is needed for all patients, then 'getting it right' for people with intellectual disabilities will benefit everyone. We welcome further and ongoing debate on the issues raised.

\section{Additional files}

Additional file 1: Overview of the practice of euthanasia and physicianassisted suicide in the Netherlands. (DOCX $16 \mathrm{~kb}$ )

Additional file 2: The Appelbaum Criteria for assessing mental capacity. (DOCX $16 \mathrm{~kb})$

\section{Abbreviations}

ASD: Autism Spectrum Disorder; EAPC: European Association for Palliative Care; EAS: Euthanasia and Assisted Suicide; ID: Intellectual disabilities; RTE: Regional Euthanasia Review Committee ("Regionale Toetsingscommissie Euthanasie"); SCEN: Support and Consultation on Euthanasia in the Netherlands

\section{Acknowledgements}

We are grateful to Robert Preston for offering advice on drafts of the manuscript.

Funding

None

\section{Availability of data and materials}

The datasets generated and analysed during the current study are publicly available (in the Dutch language) on the following website: https://www.euthanasiecommissie.nl/

English translation of the dataset is available from the corresponding author upon reasonable request.

\section{Authors' contributions}

ITW and SH planned the work. ITW collected the data and drafted the manuscript. ITW, LC, IF and SH contributed to analysing the data, discussing the implications of the results, revising the manuscript and agreeing the final version.

Ethics approval and consent to participate

The current study extracted data from publicly available online databases where no participation of individuals was involved. The need for ethics approval was waived by the Dutch Central Committee on Research Involving Human Subjects: http://www.ccmo.nl/en/non-wmo-research

Consent for publication

Not applicable (no individually identifiable data are reported in this study).

\section{Competing interests}

The authors declare that they have no competing interests.

\section{Publisher's Note}

Springer Nature remains neutral with regard to jurisdictional claims in published maps and institutional affiliations.

\section{Author details}

${ }^{1}$ Kingston University \& St George's, University of London, Cranmer Terrace, London SW7 ORE, UK. ${ }^{2}$ Governor Kremers Centre, Maastricht University Medical Centre, PO Box 616, 6200, MD, Maastricht, The Netherlands. ${ }^{3}$ Cardiff University, Velindre NHS Trust, Cardiff CF14 2TL, UK. ${ }^{4}$ St George's University of London, Cranmer Terrace, London SW17 ORE, UK.

Received: 5 October 2017 Accepted: 21 February 2018

Published online: 05 March 2018

\section{References}

1. Snyder Sulmasy L, Mueller PS. Ethics and the legalization of physicianassisted suicide: an American College of Physicians position paper. Ann Intern Med. 2017;167(8):576.

2. Radbruch L, Leget C, Bahr P, Müller-Busch C, Ellershaw J, de Conno F, van den Berghe P. Euthanasia and physician-assisted suicide: a white paper from the European Association for Palliative Care. Palliat Med. 2016;30(2):104-16.

3. Lerner B, Caplan A. Euthanasia in Belgium and the Netherlands: on a slippery slope? JAMA Int. 2015;175(10):1640-1. 
4. Frost T, Sinha D, Gilbert B. Should assisted dying be legalised? Philos Ethics, Humanit Med. 2014;9:3.

5. Krahn G. Reflections on the debate on disability and aid in dying. Disabil Health J. 2010;3(1):51-5.

6. Regionale Toetsingscommissies Euthanasie. Regional Euthanasia Review Committees Code of practice. The Hague; 2015. Available from: https://english.euthanasiecommissie.nl/the-committees/code-ofpractice. Accessed 03 Oct 2017.

7. Huxtable R, Möller M. "Setting a principled boundary"? Euthanasia as a response to "life fatigue". Bioethics. 2007;21(3):117-26.

8. Schnabel P, Meyboom-de Jong B, Schudel W, Cleiren C, Mevis P, Verkerk M, van der Heide A, Hesselmann G, Stultiëns L. Voltooid leven: Over hulp bij zelfdoding aan mensen die hun leven voltooid achten (Completed life: About assisted suicide for people who consider their life complete). The Hague; 2016. Available from: https://www.rijksoverheid.nl/onderwerpen/ levenseinde-en-euthanasie/documenten/rapporten/2016/02/04/rapportadviescommissie-voltooid-leven. Accessed 03 Oct 2017.

9. Regionale Toetsingscommissies Euthanasie. Regional Euthanasia Review Committees Annual Report 2016. The Haque; 2017. Available from: https:// english.euthanasiecommissie.nl/the-committees/documents/publications/ annual-reports/2002/annual-reports/annual-reports. Accessed 03 Oct 2017.

10. Deschepper R, Distelmans W, Bilsen J. Requests for euthanasia/physicianassisted suicide on the basis of mental suffering. JAMA Psychiatry. 2014; 71(6):617-8.

11. Price A, McCormack R, Wiseman T, Hotopf M. Concepts of mental capacity for patients requesting assisted suicide: a qualitative analysis of expert evidence presented to the commission on assisted dying. BMC Med Ethics. 2014;15(1):32.

12. Doernberg SN, Peteet JR, Kim SYH. Capacity evaluations of psychiatric patients requesting assisted death in the Netherlands. Psychosomatics. 2016;57(6):556-65.

13. Oregon Public Health Division. Oregon Death with Dignity Act: Data summary 2016. 2017. Available from: http://www.oregon.gov/OHA/PH/ ProviderPartnerResources/EvaluationResearch/DeathwithDignityAct/pages/ index.aspx. Accessed 03 Oct 2017.

14. World Health Organization Regional Office for Europe. Definition: intellectual disability. 2017. Available from: http://www.euro.who.int/en/health-topics/ noncommunicable-diseases/mental-health/news/news/2010/15/childrensright-to-family-life/definition-intellectual-disability. Accessed 03 Oct 2017.

15. American Psychiatric Association. What is autism spectrum disorder? 2017. Available from: https://www.psychiatry.org/patients-families/autism/what-isautism-spectrum-disorder. Accessed 03 Oct 2017.

16. Behuniak S. Death with "dignity": the wedge that divides the disability rights movement from the right to die movement. Polit Life Sci. 2011;30(1):17-32.

17. Fadem P, Minkler M, Perry M, Blum K, Moore L, Rogers J, Williams L. Attitudes of people with disabilities toward physician-assisted suicide legislation: broadening the dialogue. J Health Polit Policy Law. 2003;28(6): 977-1001.

18. United Nations. Convention on the rights of persons with disabilities. 2006. Available from: https://www.un.org/development/desa/disabilities/conventionon-the-rights-of-persons-with-disabilities.html. Accessed 27 Nov 2017.

19. Hsieh H, Shannon S. Three approaches to qualitative content analysis. Qual Health Res. 2005;15(9):1277-88.

20. Grisso T, Appelbaum P. Assessing competence to consent to treatment: a guide for physicians and other health professionals. New York: Oxford University Press; 1998.

21. Kim S, De Vries R, Peteet J. Euthanasia and assisted suicide of patients with psychiatric disorders in the Netherlands 2011 to 2014. JAMA Psychiatry. 2016;73(4):362-8.

22. Rijksoverheid [Government of the Netherlands]. Handreiking voor de beoordeling van wilsbekwaamheid (voor de hulpverlener) [Guide for assessing decisional capacity - for healthcare professionals]. In: The Hague; 2007.

23. Stewart C, Peisah C, Draper B. A test for mental capacity to request assisted suicide. J Med Ethics. 2011;37(1):34-9.

24. Appelbaum P. Assessment of patients ' competence to consent to treatment. N Engl J Med. 2007;357:1834-40.

25. Department for Constitutional Affairs. Mental Capacity Act 2005 (Chapter 9). London; 2005. Available from: https://www.legislation.gov.uk/ukpga/2005/9/ contents. Accessed 27 Nov 2017.
26. Breden T, Vollmann J. The cognitive based approach of capacity assessment in psychiatry: a philosophical critique of the MacCAT-T. Health Care Anal. 2004;12(4):273-83

27. Halpern J. When concretized emotion-belief complexes derail decisionmaking capacity. Bioethics. 2012;26(2):108-16.

28. Tan J, Hope T, Stewart A, Fitzpatrick R. Competence to make treatment decision in anorexia nervosa: thinking processes and values. Philos Psychiatr Psychol. 2006;13(4):267-82.

29. Hindmarch T, Hotopf M, Owen G. Depression and decision-making capacity for treatment or research: a systematic review. BMC Med Ethics. 2013;14:54.

30. Tuffrey-Wijne I, Giatras N, Goulding L, Abraham E, Fenwick L, Edwards C, Hollins S. Identifying the factors affecting the implementation of strategies to promote a safer environment for patients with learning disabilities in NHS hospitals: a mixed-methods study. Heal Serv Deliv Res. 2013;1(13):1-248.

31. Wehmeyer M, Garner N. The impact of personal characteristics of people with intellectual and developmental disability on self-determination and autonomous functioning. J Appl Res Intellect Disabil. 2003;16(4):255-65.

32. Wullink M, Widdershoven $G$, Van Schrojenstein Lantman-de Valk $H$, Metsemakers J, Dinant G. Autonomy in relation to health among people with intellectual disability: a literature review. J Intellect Disabi Res. 2009;53(9):816-26.

33. Michael J. Healthcare for all: report of the independent inquiry into access to healthcare for people with learning disabilities. London; 2008. Available from: http://webarchive.nationalarchives.gov.uk/20130107105354/http:/ www.dh.gov.uk/prod_consum_dh/groups/dh_digitalassets/@dh/@en/ documents/digitalasset/dh_106126.pdf. Accessed 03 Oct 2017.

34. Heslop P, Blair P, Fleming P, Hoghton M, Marriott A, Russ L. Confidential Inquiry into premature deaths of people with learning disabilities (CIPOLD). Bristol; 2013. Available from: http://www.bris.ac.uk/cipold/reports/index.html. Accessed 03 Oct 2017.

35. Werth J, Benjamin G, Farrenkopf T. Requests for physician-assisted death: guidelines for assessing mental capacity and impaired judgment. Psychol Public Policy Law. 2000;6(2):348-72.

36. Regional Euthanasia Review Committees. Regional Euthanasia Review Committees Annual Report 2016. The Hague: Regional Euthanasia Review Committees; 2017. Available from: https://english.euthanasiecommissie.nl/ the-committees/documents/publications/annual-reports/2002/annualreports/annual-reports. Accessed 27 Nov 2017.

37. Varelius J. Medical expertise, existential suffering and ending life. J Med Ethics. 2014;40(2):104-7.

38. McCormack R, Fléchais $R$. The role of psychiatrists and mental disorder in assisted dying practices around the world: a review of the legislation and official reports. Psychosomatics. 2012;53(4):319-26.

39. Kanne S. Diagnostic overshadowing. In: Volkmar F, editor. Encyclopedia of autism Spectrum disorders. New York: springer science + business. Media. 2013:938-40.

40. Mccrae N, Bloomfield J. Mental health nursing and the debate on assisted dying. J Psychiatr Ment Health Nurs. 2013;20(7):655-61.

41. Mencap. Death by indifference : 74 deaths and counting. London; 2012. Available from: https://www.mencap.org.uk/sites/default/files/2016-08/ Death\%20by\%20Indifference\%20-\%2074\%20deaths\%20and\%20counting.pdf. Accessed 03 Oct 2017

42. Green B, Bruce M-A, Finn P, Wright A, Daniel D, Povey J, et al. Independent review of deaths of people with a learning disability or mental health problem in contact with southern health NHS foundation trust April 2011 to March 2015. London: Mazars; 2015.

43. Snijdewind M, Willems D, Deliens L, Onwuteaka-Philipsen B, Chambaere K. A study of the first year of the end-of-life clinic for physician-assisted dying in the Netherlands. JAMA Intern Med. 2015:175(10):1633-40.

44. Tuffrey-Wijne I, McLaughlin D, Curfs L, Dusart A, Hoenger C, McEnhill L, Read S, Ryan K, Satgé D, Straßer B, Westergård B, Oliver D. Defining consensus norms for palliative care of people with intellectual disabilities in Europe, using Delphi methods: A White Paper from the European Association of Palliative Care (EAPC). Palliative Medicine. 2015;30(5):446-455. https://doi.org/10.1177/0269216315600993. 